\title{
The Impact of Dedicated Aortic Teams and Centralisation of Aortic Services, and Surgeon or Centre Specific Volumes on Outcomes of Acute Type A Aortic Dissection
}

\author{
Amer Harky ${ }^{1 *}$, Jeffrey Shi Kai Chan² ${ }^{2}$ Ciaran Grafton-Clarke ${ }^{3}$ and Ahmed Al-Adhami ${ }^{4}$ \\ ${ }^{1}$ Department of Vascular Surgery, Countess of Chester Hospital, UK \\ ${ }^{2}$ Faculty of Medicine, The Chinese University of Hong Kong, $\mathrm{HK}$ \\ ${ }^{3}$ School of Medicine, University of Liverpool, UK
}

${ }^{4}$ Department of Cardiothoracic Surgery, Golden Jubilee National Hospital, UK

Submission: July 06, 2018; Published: August 24, 2018

*Corresponding author: Amer Harky, Department of Vascular Surgery, Countess of Chester Hospital Chester, CH2 1UL, United Kingdom, Email: aaharky@gmail.com

Keywords: Aortic dissection; Surgeon volume; Aortic team

\section{Introduction}

Acute Type A aortic dissection (ATAAD) is a surgical emergency with a high expected mortality and morbidity particularly if not managed operatively within the first 24 hours $[1,2]$. The gold standard treatment for aortic dissection remains open surgical repair [3] and although the mortality rates can be as high as $90 \%, 75 \%$ - 90\% long term survival rates can be achieved if treatment is immediately constituted in the form of open surgical repair [4]. Survival in patients with ATAAD is however variable with multifactorial predictors and determinants. Reports from the International Registry of Acute Aortic Dissection (IRAD) and the Society for Cardiothoracic Surgery in Great Britain and Ireland have reported operative mortality rates of $25.1 \%$ and $22.8 \%$ respectively $[5,6]$. In contrast, the German registry for Acute Aortic Dissection Type A (GERAADA) has reported lower mortality rates (17\%) [7] and even lower motility figures of less than $10 \%$ being published by several single-centre studies [8-10]. In this short review we aim the impact of dedicated aortic teams, and surgeon or centre specific volumes on outcomes of acute type A aortic dissection.

\section{Individual surgeon and centre volume - high versus low volume}

In a multi-centre national observational database study examining the surgeon volume-outcome relationship, Bashir et al. [3] evaluated data from 1550 patients who underwent ATAAD repair by 249 individual consultant surgeons across United
Kingdom (UK) between 2007 and 2013. Although overall operative mortality was $18.3 \%$, on multivariate analysis operating surgeons with a mean annual volume of 4 cases or less exhibited higher operative mortality rates than those with higher mean annual volumes $(19.3 \%$ vs $12.6 \%$ respectively, $\mathrm{p}=0.015)$. Furthermore, in two separate large North-American studies undertaken by Chikwe et al. [11] and Kinpp et al. [12], outcomes of 5184 and 3013 patients with acute aortic dissections, respectively, were analysed. Both studies evaluated the effects of centre volumes on operative mortality but Chikwe and colleagues however have also assessed the impact of individual surgeon volume on outcomes and overall performance. Chikwe et al. [11] reported that surgeons with an average of less than 1 aortic dissection repair annually had a mean operative mortality of $27.5 \%$, compared with $17.0 \%$ for those performing 5 or more such procedures annually (odds ratio 1.78; 95\% confidence interval 1.39 to 2.29; p < 0.001). A similar inverse relationship was seen between institution volume and operative mortality with higher mortality rates $(27.4 \%$ versus $16.4 \%$; $p$ 0.001) in low volume institutions ( 3 or fewer acute aortic dissection repairs per year) than high volume centres (13 or more aortic dissection annually). Despite disagreements in what defines low, medium or high-volume surgery, there was consensus in both studies on the effect of centre volume on mortality with high volume centres reporting lower mortality rates than their lower volume counterparts. Annual operative volume was inversely proportional with mortality. 
Similarly, in a systematic review of 79,131 patients by Mariscalclo and colleagues [13], high-volume centres or individual surgeons had lower mortality rates (OR 0.51 ; $95 \%$ CI $0.46-0.56$, and OR $0.41,95 \% \mathrm{CI} 0.25-0.66$, respectively). All these findings were also corroborated by several studies supporting the idea that ATAAD should be managed by high volume centres and highvolume operating surgeons [14-16].

\section{Dedicated aortic teams - does it impact the outcome?}

Although It is clear from published literature that patients with ATAAD have better outcomes if treated in high volume centres by high-volume surgeons [3,10-16]. However, the impact of establishing dedicated teams for aortic surgery on the perioperative outcomes is less well studied [17].

In a large study by Andersen etal. [18], outcomes of 128 patients undergoing surgery before (56 patients) and after (72 patients) the introduction of a multidisciplinary Thoracic Aortic Surgery Program (TASP) with a dedicated aortic team were analysed. Reported operative mortality rates significantly improved from $33.9 \%$ to $2.8 \%$. These results were further supported by a recent systematic review of observational studies [13] concluding that centres with specific multidisciplinary aortic programmes and dedicated on-call aortic teams showed a significant reduction in mortality following surgery for acute aortic syndrome (OR 0.31; 95\% CI 0.19-0.5, and OR 0.37; 95\% CI 0.15-0.87, respectively).

Several other studies have taken further steps and have reported on the impact of a dedicated on- call aortic team and multidisciplinary meeting that resulted in improved perioperative outcomes, especially lower mortality rates [19-21]. Among those studies, Lenos et al. [19] reported a lower mortality rate in centres with a TASP ( $4 \%$ vs $21.8 \%, \mathrm{p}<0.001$ ), and similarly Beller and associates [20] report improved mortality $(9.7 \%$ vs $30.8 \%, \mathrm{P}=0.014$ ) in their single centre following introduction of multidisciplinary aortic surgery team and standardised management protocols for ATAAD patients. Moreover, in a study evaluating outcomes of general thoracic aortic surgery, Sales et al. [21] reported a total reduction in all-cause operative mortality (9.7\% vs $22.9 \%, p=0.008$ ) after introduction of the Centre of Aortic Surgery highlighting its importance of dedicated aortic teams in achieving better outcomes.

With regionalisation and centralisation of subspecialist services such as aortic surgery, it is evident that this there are several advantages, including the positive volume-outcome effect and concentration of resources. In contrast however, it is also important to note that centralisation is almost invariably associated with reduced access to subspecialist services and any such steps must be accompanied with an analysis of the regional geography, population and needs.

\section{Conclusion}

Published literature surrounding the impact of centralisation of aortic services (with dedicated on-call and aortic multidisciplinary teams) including the management patients with type A aortic dissection is growing with increasing supportive evidence to suggest improved mortality and morbidity. Surgeon and institutional case volume were independently associated with improved outcomes after aortic dissection repair.

\section{References}

1. Kar-Mun CW, Schneider JI (2009) High-risk chief complaints I: chest pain-the big three. Emergency medicine clinics of North America 27: 685-712.

2. Borrelli M, Young C, Attia R (2018) Is there a Volume-Outcomes Relationship for Patients Undergoing Surgical Management of Acute Stanford Type A Aortic Dissection? J Cardiovasc Dis Diagn 6(2): 311

3. Bashir M, Harky A, Fok M, Shaw M, Hickey GL, et al. (2017) Acute type A aortic dissection in the United Kingdom: Surgeon volume-outcome relation. J Thorac Cardiovasc Surg 154(2): 398-406.

4. Ranasinghe AM, Strong D, Boland B, Bonser RS (2011) Acute aortic dissection. BMJ 343: 4487.

5. Trimarchi S, Nienaber CA, Rampoldi V, Myrmel T, Suzuki T, et al. (2005) Contemporary results of surgery in acute type A aortic dissection: The International Registry of Acute Aortic Dissection experience. J Thorac Cardiovasc Surg 129(1): 112-122.

6. Bridgewater B, Keogh B, Kinsman R, Walton P (2008) Sixth National Adult Cardiac Surgical Database Report. Society for Cardiothoracic Surgery in UK and Ireland and Dendrite Clinical Systems Ltd, London, England, UK.

7. Kruger T, Conzelmann LO, Bonser RS, Borger MA, Czerny M, et al. (2012) Acute aortic dissection type. A Br J Surg 99: 1331-1344.

8. Sun L, Qi R, Zhu J, Liu Y, Chang Q, et al. (2011) Repair of acute type A dissection: our experiences and results. Ann Thorac Surg 91(4): 11471152.

9. Andersen ND, Ganapathi AM, Hanna JM, Williams JB, Gaca JG, et al. (2014) Outcomes of acute type a dissection repair before and after implementation of a multidisciplinary thoracic aortic surgery program. J Am Coll Cardiol 63(17): 1796-1803.

10. Komatsu K, Takano T, Terasaki T, Wada Y, Seto T, et al. (2014) Surgical outcomes of acute type A aortic dissection in elderly patients. Ann Thorac Surg 97(5): 1576-1578.

11. Chikwe J, Cavallaro P, Itagaki S, Seigerman M, DiLuozzo G, et al. (2013) National outcomes in acute aortic dissection: influence of surgeon and institutional volume on operative mortality. Ann Thoracic Surg 95(5): 1563-1569.

12. Knipp BS, Deeb GM, Prager RL, Williams CY, Upchurch GR, et al. (2007) A contemporary analysis of outcomes for operative repair of type A aortic dissection in the United States. Surgery 142(4): 524-528.

13. Mariscalco G, Maselli D, Zanobini M, Ahmed A, Bruno VD, et al. (2018) Aortic centres should represent the standard of care for acute aortic syndrome. Eur J Prev Cardiol 25(1suppl): 3-14.

14. Iribarne A, Milner R, Merlo AE, Singh A, Saunders CR, et al. (2015) Outcomes following emergent open repair for thoracic aortic dissection are improved at higher volume centers. J Cardiac Surg 30(1): 74-79.

15. Merlo AE, Chauhan D, Pettit C, Hong KN, Saunders CR, et al. (2016) Outcomes following emergent open repair for thoracic aortic dissection are improved at higher volume centers in direct admissions and transfers. J Cardiothoracic Surg 11(1): 118.

16. Zimmerman KP, Oderich G, Pochettino A, Hanson KT, Habermann EB, et al. (2016) Improving mortality trends for hospitalization of aortic dissection in the National Inpatient Sample. J Vasc Surg 64(3): 606615 . 
17. Preventza $O$ (2017) In type A aortic dissection repair, an effective team approach and relational coordination are more important for patients' outcomes than surgeon volume. J Thorac Cardiovasc Surg 154(2): $407-$ 408.

18. Andersen ND, Ganapathi AM, Hanna JM, Williams JB, Gaca JG, et al (2014) Outcomes of acute type a dissection repair before and after implementation of a multidisciplinary thoracic aortic surgery program. J Am Coll Cardiol 63(17): 1796-1803.

19. Lenos A, Bougioukakis P, Irimie V, Zacher M, Diegeler A, et al. (2014)
Impact of surgical experience on outcome in surgery of acute type A aortic dissection. Euro J Cardio-Thoracic Surg 48(3): 491-496.

20. Beller JP, Scheinerman JA, Balsam LB, Ursomanno P, DeAnda A (2015) Operative strategies and outcomes in type a aortic dissection after the enactment of a multidisciplinary aortic surgery team. Innovations (Phila) 10(6): 410-415.

21. Sales MdC, Frota Filho JD, Aguzzoli C, Souza LD, Rösler ÁM, et al. (2014) Aortic Center: specialized care improves outcomes and decreases mortality. Rev Bras Cir Cardiovasc 29(4): 494-504.

\section{Your next submission with Juniper Publishers} will reach you the below assets

- Quality Editorial service

- Swift Peer Review

- Reprints availability

- E-prints Service

- Manuscript Podcast for convenient understanding

- Global attainment for your research

- Manuscript accessibility in different formats

( Pdf, E-pub, Full Text, Audio)

- Unceasing customer service

Track the below URL for one-step submission https://juniperpublishers.com/online-submission.php 